\title{
Autonomía indígena en disputa: entre la reconstitución comunitaria y la tutela estatal. La experiencia guaraní de Huacaya en Bolivia
}

Indigenous Autonomy in Dispute: Between Community Reconstruction and State Tutelage. The Guaraní Experience of Huacaya in Bolivia Autonomie autochtone en litige: entre la reconstitution communautaire et la tutelle de l'État. L'expérience guarani de Huacaya en Bolivie

Pabel Camilo López Flores y Gaya Makaran

\section{OpenEdition}

Journals

Edición electrónica

URL: http://journals.openedition.org/rccs/10159

DOI: $10.4000 /$ rccs.10159

ISSN: 2182-7435

Editor

Centro de Estudos Sociais da Universidade de Coimbra

Edición impresa

Fecha de publicación: 1 mayo 2020

Paginación: 49-70

ISSN: 0254-1106

Referencia electrónica

Pabel Camilo López Flores y Gaya Makaran, « Autonomía indígena en disputa: entre la reconstitución comunitaria y la tutela estatal. La experiencia guaraní de Huacaya en Bolivia », Revista Crítica de Ciências Sociais [En línea], 121 | 2020, Publicado el 15 abril 2020, consultado el 17 abril 2020. URL : http://journals.openedition.org/rccs/10159; DOI : https://doi.org/10.4000/rccs.10159

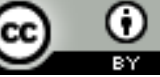




\title{
Autonomía indígena en disputa: entre la reconstitución comunitaria y la tutela estatal. La experiencia guaraní de Huacaya en Bolivia
}

\begin{abstract}
Pasado más de un decenio desde la aprobación de la actual Constitución boliviana que viabilizaba la creación de las autonomías indígenas, actualmente la mayoría de los procesos autonómicos no parecen avanzar en la dirección esperada. ¿Qué sucedió con las Autonomías Indígenas Originarias Campesinas, uno de los componentes más transformadores del proyecto plurinacional en Bolivia? En este trabajo tratamos de problematizar este interrogante a partir de los procesos autonómicos del pueblo guaraní en el Chaco boliviano, concretamente en el municipio de Huacaya. Analizamos críticamente este proceso de la "autonomía de derecho" a partir de las voces de los propios sujetos indígenas, en un esfuerzo por repensar tanto el concepto mismo de la autonomía indígena, como su aplicación concreta en Bolivia.
\end{abstract}

Palabras-clave: autonomía; Guaraní (pueblo); Huacaya (Bolivia); movimiento indígena; plurinacionalidad.

Palavras-chave: autonomia; Guarani (povo); Huacaya (Bolívia); movimento indígena; plurinacionalidade.

\section{Introducción}

En Bolivia, el horizonte de la transformación estatal a través de la construcción de un Estado plurinacional situó como uno de sus núcleos centrales el reconocimiento de las Autonomías Indígenas, como propuesta concreta para transitar hacia la democratización y, a su vez, la descolonización misma del Estado, como condición para hacer posible la plurinacionalidad. Esto se habría originado en la potencia y resistencia de los pueblos indígenas y los sujetos comunitarios, acumuladas durante siglos de dominación colonial y republicana, que resurgieron de manera contundente a finales del siglo xx e inicios del siglo Xxi. Entonces, tanto la plurinacionalidad como la autonomía 
indígena ${ }^{1}$ serían fruto de imaginarios colectivos, reivindicaciones históricas y luchas políticas de movimientos sociales de carácter indígena, que desembocarán en el mandato de construcción de un "Estado plurinacional comunitario y con autonomías" (CPE, 2009), y esto implicaba romper con el monopolio de la política, es decir, conllevaría la instauración y el desarrollo de una pluralidad de espacios y formas de autogobierno indígena (Tapia Mealla, 2011).

En el 2009, con la aprobación de la actual Constitución Política del Estado (CPE) con un nuevo régimen autonómico y con la entrada en vigor de la Ley Marco de Autonomías y Descentralización (LMAD) en 2010, las autonomías indígenas pasarán de un ámbito de tensión y conflicto a una dinámica más "administrativa" y "legal" a nivel territorial, enfocada en el "proceso estatuyente”, según Exeni (2015). Es decir, en la elaboración de estatutos autonómicos y el seguimiento del trámite estipulado por el respectivo marco normativo, después de que el 6 de diciembre del 2009 once municipios expresaran, vía referéndum, su voluntad de convertirse en Autonomías Indígenas Originarias Campesinas (AIOC), sin contar todavía con el marco legal para tal propósito.

El tema de las autonomías indígenas tiene como uno de los protagonistas e impulsores principales al pueblo guaraní del Chaco boliviano, autoidentificado como "Nación Guaraní", organizado política y territorialmente con base en sus comunidades, sus autoridades tradicionales y su organización matriz, la Asamblea del Pueblo Guaraní (APG), que desde hace décadas reivindica la reconstitución comunitaria de su territorio ancestral, logrando incorporar y disputar su demanda autonómica en el proceso constituyente boliviano de la década pasada. ${ }^{2}$ De ahí que el territorio guaraní se convierte en un campo experimental de construcción y disputa de la

\footnotetext{
${ }^{1}$ Es importante precisar que la reivindicación de las "autonomías" no era en su inicio una consigna central del movimiento indígena boliviano, que más bien reivindicaba el reconocimiento como pueblos y/o naciones originarias con sus propios sistemas de autogobierno y autoridad, de gestión territorial y reproducción económica comunitarias. La bandera autonómica será objeto de disputa a partir del uso instrumental que harían de ella las élites regionales de la llamada "media luna" (Departamentos de Santa Cruz, Beni, Pando y Tarija), contra el surgimiento de movimientos sociales de perfil campesino-indígena como una estrategia política de oposición y negociación con el gobierno del Movimiento al Socialismo, en los años 2006-2008.

${ }^{2}$ La APG, a partir de su protagonismo en movilizaciones colectivas, participa en la Asamblea Constituyente con una propuesta política, resultado de un intenso proceso de consulta, discusión y construcción participativa de las comunidades en 25 capitanías guaraníes del Chaco, que apunta a una autonomía político-territorial plena que incluye el "control sobre los recursos naturales", la "desestructuración del Estado colonial”, la "reterritorialización” y la "reconstitución de la Nación Guaraní". El documento final, denominado "ORE NEMONGETA. Propuesta para la Asamblea Constituyente" que se presentó oficialmente en 2006 a la Asamblea Constituyente, tiene como eje central el tema territorial: "El gran objetivo es la liberación en función del territorio" (APG, 2006: 1); junto con la preocupación por la identidad del pueblo guaraní, con una clara referencia a los procesos históricos de colonialismo y dominación, que continuaron durante la época republicana de Bolivia, hasta nuestros días. De esta manera, la APG propone una definición de la autonomía,
} 
autonomía indígena, la cual que se fue materializando en dos municipios con mayoría poblacional guaraní, Charagua (Departamento de Santa Cruz) y Huacaya (Departamento de Chuquisaca), que desarrollaron sus procesos estatutarios para la conversión en autonomías indígenas, con base en la CPE y la LMAD, mediante intensos procesos de consulta y discusión en las comunidades y sus instancias organizativas, que plasmaron en los estatutos un conjunto de principios basados en la cosmovisión guaraní y que se materializó en la propuesta del autogobierno indígena.

Precisamente, una lectura analítica de estos procesos autonómicos indígenas nos permitirá problematizar y en cierta medida explicar por qué, a diferencia del supuesto "proceso exitoso" del municipio de Charagua, en el caso del municipio de Huacaya se suspenderá el camino hacia la autonomía tras el fracaso del referéndum estatutario. Este complejo fenómeno suscita algunos interrogantes, entre otros, referidos al proceso desarrollado en estos territorios, las condiciones y el alcance del actual proceso autonómico indígena en Bolivia, que además tiene como trasfondo las tensiones con el Estado para consolidar la autonomía de estos y otros territorios indígenas en las tierras bajas, en un contexto adverso de intensificación de un modelo extractivista.

Desde una perspectiva crítica, este texto se propone abordar la experiencia de la autonomía indígena guaraní en el Chaco boliviano y de manera específica en el municipio de Huacaya, en un contexto de acentuación de las políticas extractivistas del gobierno del Movimiento al Socialismo (MAS) con Evo Morales a la cabeza, donde a la vez se viene cuestionando profundamente el supuesto proyecto "plurinacional" que retóricamente este gobierno decía impulsar y que será desmentido por la realidad de las modalidades de relanzamiento del Estado nación y de recentralización monopólica de la política concentrada en el partido gobernante. Para este propósito, buena parte de este trabajo se basa en la evidencia empírica, a partir de la información recolectada en el 2017 en varias zonas y comunidades guaraníes del Chaco boliviano a través de fuentes directas,

como un paso hacia la autodeterminación de los pueblos, su libertad y su búsqueda de una "sociedad otra" enraizada en el territorio ancestral. Asimismo, sobre los principios y premisas, dentro de la propuesta presentada por la APG a la Asamblea Constituyente, se especifican una serie de "competencias" sobre las que las autonomías indígenas debían tener facultades, tales como: territorio, tierra, propiedad del subsuelo, recursos renovables y no renovables (hidrocarburos y minerales), agua y desarrollo propio. De este modo, a partir de la definición de autonomía indígena, el pueblo guaraní se autodefine y apunta a la autodeterminación como "Nación Guaranín" a partir de la construcción de un modelo de Gobierno Indígena Guaraní dentro de su territorio, que a su vez está dirigido a fortalecer y consolidar la nueva estructura orgánica en todos sus niveles como: tëta (comunidad), tëtaguasu (zona) y ñemboatiguasu (asamblea nacional) (APG, 2006). 
principalmente testimonios recogidos mediante entrevistas a los/las dirigentes guaraníes actuales e históricos, que constituyen el sujeto autonómico en este caso. Así, partiremos de una pregunta inspirada en la coyuntura actual -el porqué del fracaso del referéndum autonómico en Huacaya-, que nos servirá de pretexto para analizar los condicionamientos internos y externos que frenan los procesos autonómicos en Bolivia y, en cierta medida, en América Latina. ${ }^{3}$ A partir de la mirada de los propios sujetos indígenas y cómo evalúan el actual proceso autonómico, tejemos nuestro análisis, en un esfuerzo por repensar tanto el concepto mismo de la autonomía como, sobre todo, su materialización concreta, que en este caso se verá atravesada por las lógicas estatales de una "autonomía de derecho", o según Burguete Cal y Mayor (2010), un tipo de "autonomía otorgada por el Estado". En este sentido, nuestro acercamiento detallado al estudio del caso pretende ir más allá de una simple descripción y contribuir para la reflexión teórica sobre la(s) autonomía(s) indígenas en el contexto latinoamericano, desde una perspectiva comprometida con la experiencia concreta de los procesos autonómicos de los sujetos comunitarios.

\section{El Estado plurinacional y la institucionalización de las autonomías}

En el año 2009, a partir de la promulgación de la nueva CPE, Bolivia transformó, al menos declarativamente, el carácter de su estatalidad que también habría sido producto de una crisis política y del propio Estado nación (Tapia, 2007). Así, el núcleo central del horizonte de transformación estatal que instituye el nuevo marco constitucional es el carácter de "Estado plurinacional”, que se reconoce como la base y el horizonte de construcción de una nueva institucionalidad política y el referente que resume el nuevo "pacto social" que permitiría "refundar el Estado" (Santos, 2010). En ese sentido, uno de los aspectos centrales que reconfiguran estructuralmente el carácter de plurinacionalidad en la nomenclatura estatal, es el reconocimiento de la preexistencia de los pueblos y naciones indígenas y originarias (CPE, 2009, art. 2).

Asimismo, la organización territorial ha sido objeto de un importante cambio al transitar hacia un Estado que se define como "unitario" y "autonómico" a la vez; esto implicó una redefinición político-territorial y una democratización del poder estatal. Esta transición a un tipo de "Estado con autonomías", aunque no es algo nuevo dentro de las modalidades de estatalidad a nivel internacional, constituyó una gran innovación por el

\footnotetext{
${ }_{3}^{3}$ Para profundizar sobre el tema de la autonomía en América Latina en sus diversas facetas, incluida la indígena, véase Makaran et al. (2019).
} 
reconocimiento de la AIOC en su estructura territorial, como un ámbito autonómico y una entidad territorial específica, estableciendo que:

La autonomía indígena originaria campesina consiste en el autogobierno como ejercicio de la libre determinación de las naciones y los pueblos indígena originario campesinos, cuya población comparte territorio, cultura, historia, lenguas, y organización o instituciones jurídicas, políticas, sociales y económicas propias. (CPE, 2009, art. 289)

En ese sentido, el rediseño político-territorial que se estableció a partir del régimen de autonomías en la nueva estructura y organización territorial del Estado plurinacional implicaba en inicio un proceso de desconcentración, democratización y redistribución del poder político en el territorio. De esta manera, el reconocimiento constitucional de las autonomías indígenas se convirtió en uno de los puntales para la concreción de la plurinacionalidad, ya que implica no sólo el reconocimiento de tipo cultural de la autonomía territorial, en un país de condición multisocietal (Tapia, 2002), sino el desafío de descolonizar los históricos esquemas de poder en los territorios.

Posteriormente, en julio del 2010 se promulga la LMAD, norma de "desarrollo constitucional" dirigida a regular el régimen de las autonomías y establecer las bases para la organización territorial del Estado. Asimismo, la LMAD realiza una precisión conceptual de las nociones con relación a las autonomías indígenas, como la figura del Territorio Indígena Originario Campesino (TIOC). ${ }^{4}$ El proceso de elaboración de esta ley fue complejo y polémico, atravesado por una dinámica de debates y querellas entre el Estado y las organizaciones indígenas, cuyas propuestas en su mayoría no fueron consideradas. En ese sentido, en el contexto de la elaboración de la ley se podrían identificar al menos dos posiciones contrapuestas entre el gobierno del MAS y las organizaciones; por parte del primero fue evidente la voluntad de "reducir" los alcances de la autonomía indígena, mientras que por parte de las organizaciones se demandaba una autonomía plena como el derecho a la autodeterminación y el autogobierno de los pueblos indígenas o las naciones originarias (Garcés, 2013).

Entre las controversias en torno a la LMAD se encontraban las siguientes: la reducción del alcance de la noción de "territorio ancestral" con la

\footnotetext{
${ }_{4}$ "Territorio Indígena Originario Campesino. Es el territorio ancestral sobre el cual se constituyeron las tierras colectivas o comunitarias de origen debidamente consolidadas conforme a ley, y que ha adquirido esta categoría mediante el procedimiento correspondiente ante la autoridad agraria [...]. En aquellos casos en el que el territorio indígena originario campesino cumpla los requisitos establecidos en la presente norma, se conformará en éste un gobierno autónomo indígena originario campesino" (LMAD, 2010, art. 6).
} 
delimitación político-territorial de las autonomías indígenas bajo los límites y parámetros del municipio (diseño colonial/republicano); la tendencia a subordinar a las AIOC a otras autonomías como la departamental; el debate sobre el proceso de elaboración, aprobación y control constitucional para la "legalidad" de los estatutos autonómicos indígenas; el tema de las competencias sobre los recursos naturales dentro de los territorios indígenas; el derecho de consulta previa a los pueblos indígenas y el cumplimiento de los convenios internacionales y de la propia CPE. Finalmente, la LMAD estableció los siguientes pasos en el procedimiento legal para la transformación en una AIOC: realización de un referéndum autonómico donde un municipio o un TIOC exprese mayoritariamente su voluntad de transformación en una AIOC; contar con el "certificado de la ancestralidad"; establecer un órgano estatuyente y elaborar el estatuto autonómico; contar con el "control de constitucionalidad" del estatuto por parte del Tribunal Constitucional Plurinacional (TCP); realizar un segundo referéndum autonómico donde se acepte el estatuto, y establecer el gobierno autonómico. Dichos procedimientos, más complicados y largos con relación a cualquier otra autonomía no indígena, además de burocratizar innecesariamente el proceso, niegan sistemáticamente el principio de la autodeterminación de los pueblos indígenas al subordinarlos al control estatal, basado en la lógica liberal y la jurisdicción republicana clásica. De hecho, dicha ley introduce una serie de "candados" legales que limitan y/o impiden acceder a las AIOC a gran parte de los pueblos indígenas, al continuar manteniendo los límites territoriales del viejo Estado nación republicano y del antiguo orden colonial.

Desde la promulgación del actual texto constitucional, sobre todo en los dos últimos gobiernos del MAS (2010-2014; 2015-2019), se asiste al despliegue de un proyecto estatal que en la práctica, tanto en el conjunto de normas como en sus políticas concretas, no sólo ha operado un retroceso en lo más "transformador" de la Constitución y una negación de las posibilidades reales de descolonización -minando así las condiciones de construcción de un Estado plurinacional- sino que resulta innegable y más que paradójica la forma en que desde la institucionalidad estatal, en una versión anacrónica de un nacionalismo estadocéntrico e hiperpresidencialista, se promovió un nuevo ciclo de expansión capitalista sobre territorios comunitarios ancestrales, en su mayor parte reconocidos como colectivos, y

\footnotetext{
${ }^{5}$ Entre de esos "candados" estarían, por ejemplo: la exigencia de un límite poblacional; la prohibición de afectar los límites territoriales de los departamentos y la necesidad de un "certificado de ancestralidad" (demostrable según parámetros "legales") que garantice a los pueblos indígenas gozar de los derechos colectivos, que están formalmente reconocidos en la nueva CPE (Garcés, 2013).
} 
sobre áreas protegidas y ecosistemas de gran vulnerabilidad (véase Makaran y López, 2018). En ese sentido, de manera específica en lo que respecta a las AIOC, se hace evidente que el gobierno del MAS apostó por limitarlas, obstaculizarlas, tutelarlas y subordinarlas, lo que correspondería a una ambición monopólica en lo político y al giro hiperextractivista en cuanto al modelo económico. Esta tendencia ya se puso de manifiesto en el caso de la primera AIOC, la Autonomía Guaraní en Charagua, ${ }^{6}$ tanto en su largo y condicionado proceso de transformación, como sobre todo en la sujeción gubernamental y partidista del nuevo gobierno autonómico, pero tomó fuerza y se evidenció de manera inequívoca en la experiencia autonómica de Huacaya entorpeciendo, saboteando y hasta abortando el proceso.

\section{Huacaya... ¿por qué ganó el "no" a la "Autonomía Indígena"?}

Huacaya, ${ }^{7}$ un municipio mayoritariamente guaraní en el Departamento de Chuquisaca en el Chaco boliviano, junto con Charagua se encaminó en el 2009 hacia la autonomía, proceso que hasta hoy se encuentra prácticamente paralizado debido a la victoria del "no" en el último referéndum sobre el Estatuto Autonómico realizado el 9 de julio del 2017, con un 58,60 \% de votos de rechazo.

\footnotetext{
${ }^{6}$ El municipio de Charagua, ubicado en la región del Chaco, provincia de Cordillera, al sur del Departamento de Santa Cruz, es el más grande de Bolivia $\left(74424 \mathrm{~km}^{2}\right)$, presenta una gran heterogeneidad y complejidad cultural, y es el municipio del Chaco con más población guaraní. La Autonomía Guaraní Charagua Iyambae es la primera "autonomía indígena de derecho" en todo el país. En julio del 2009, las capitanías guaraníes de Charagua decidieron presentarse para el referéndum de transformación en AIOC, cuyo resultado fue un $56 \%$ de apoyo al proyecto autonómico. En junio del 2012 se aprobó el Estatuto, tras el respectivo "control de constitucionalidad" efectuado por el TCP que contempló 22 artículos como incompatibles con la Constitución, los cuales tuvieron que ser reformulados. El proyecto de estatuto fue sometido a un "referéndum aprobatorio" en el 2016, donde la mayoría de la población lo refrendó para que de inmediato se comenzara a ejercer el autogobierno indígena en enero del 2017. En ese escenario, desde que se declaró formalmente a Charagua como la primera Autonomía Indígena en Bolivia comenzaron a surgir los límites y las contradicciones, principalmente referidas a la reproducción de los esquemas burocráticos y los vicios del municipalismo, a lo que se sumó la intromisión y el control legal y político del partido gobernante sobre esta experiencia "autonómica". Según las voces de los propios sujetos guaraníes de otras zonas del Chaco, todo esto representaría un "mal ejemplo" para los procesos autonómicos del pueblo guaraní y los pueblos indígenas de las tierras bajas.

${ }^{7}$ Huacaya es un municipio que se divide en dos zonas: Santa Rosa y Huacaya. La zona de Santa Rosa cuenta con 11 comunidades guaraníes de propiedad colectiva de la tierra: Mandiyuti, Villa Mercedes, Camatindi, Camatindimi, Yaperenda, Santa Rosa, Itironque, Irenda, Imbochi, Chimbe, Karuturi; y dos comunidades campesinas de propiedad individual de la tierra: La Laguna, Tabayerupa. La zona de Huacaya cuenta con seis comunidades guaraníes: Itangua, Huacayareape, Mbororigua, Guiraitati, Iñiay, Mboikovo; tres comunidades campesinas: Ancahuasu, Kururuy, Carumpa; y un espacio urbano de Villa de Huacaya. En conjunto son 17 comunidades (capitanías) indígenas guaraní y cinco comunidades campesinas. Podemos distinguir tres niveles de estructura organizativa: comunal, zonal e interzonal. A nivel comunal tenemos capitanías comunales con la autoridad de mburuvicha o capitán; a nivel zonal tenemos la capitanía zonal con mburuvicha guasu o capitán zonal.
} 
Desde el primer referéndum por la transformación vía municipio en una autonomía indígena, donde el "sí" se impuso con una leve ventaja, hasta el último, donde se rechazó el proyecto autonómico por un importante margen, pasaron ocho largos años llenos de obstáculos y contradicciones que nos muestran el sinuoso camino de las autonomías institucionalizadas. El primer gran reto fue la convocatoria de una asamblea estatutaria y la elaboración del Estatuto Autonómico, que tardó tres años entre la carencia de fondos, los debates, las discusiones internas y la necesidad de adecuación de sus contenidos a la normativa nacional. Una vez elaborado, el Estatuto fue enviado al TCP para obtener su "Declaración de Constitucionalidad", trámite que demoró otros dos años y se exigió a los estatuyentes la modificación de varios artículos del documento, algunos de ellos cruciales. Desde la obtención de la compatibilidad constitucional en diciembre del 2014, hasta la convocatoria al referéndum aprobatorio del Estatuto en julio de 2017, transcurrieron casi tres años más; este retraso se debió principalmente a la falta de recursos.

Acerca de aquel proceso autonómico, en los siguientes párrafos analizaremos algunos testimonios de dirigentes guaraníes, tanto actuales como históricos, del municipio Huacaya con la finalidad de mostrar los claroscuros del proceso y, sobre todo, identificar las causas del fracaso, al menos momentáneo, de la propuesta autonómica. Además, nuestro propósito es ilustrar las tendencias descritas anteriormente y también detectar algunos fenómenos nuevos; esto nos permitirá llegar a un diagnóstico tentativo de los problemas que inevitablemente encuentra el proyecto autonómico guaraní en particular y las autonomías institucionales en general, y que al mismo tiempo entorpecen la realización de la autonomía tal y como la definió la APG en su propuesta.

De los testimonios recogidos se desprende la imagen de un proceso autonómico fuertemente conflictivo y contradictorio, surcado por divisiones internas, presiones y condicionamientos externos, y una sucesiva pérdida de legitimidad entre la población guaraní del municipio, factores que finalmente determinaron la derrota del proyecto en el referéndum del 9 de julio del 2017. Uno de los principales problemas denunciados era el sabotaje habitual del transcurso autonómico guaraní por parte del gobierno municipal, vinculado con la agenda antiautonómica del gobierno central, ambos del MAS: "Por ejemplo el tema del gobierno municipal, principal obstáculo para nosotros es el mismo alcalde [del MAS]"; "Tantos obstáculos que le

\footnotetext{
${ }^{8}$ Entrevista con la dirigente responsable de género, Aruchari Cuellar, Santa Rosa, municipio de Huacaya, el 17 de abril del 2017. Esta y las demás entrevistas fueron realizadas por ambos autores.
} 
pusieron los gobiernos municipales, porque los opositores que están en el gobierno municipal no quieren, no les conviene."

"El gobierno no quiere la autonomía de Huacaya", dicen todos y enumeran un sinfín de obstáculos que se les ha puesto desde que iniciaron su proceso de transformación: desde la misma legislación "plurinacional" que, como hemos demostrado, viola el principio de la ancestralidad y la autodeterminación de las naciones indígenas, hasta las maniobras directas como la infiltración de la asamblea estatutaria a fin de paralizar sus trabajos, la negación del presupuesto para el referéndum, la cooptación de los dirigentes, la desinformación de las bases e incluso la represión de los mburuvichas (autoridades) insumisos.

La negatividad de los gobiernos municipales frente a las ambiciones autonómicas del pueblo guaraní, así como también la de otros tantos pueblos originarios, se explica fácilmente tomando en cuenta que, una vez aplicada la autonomía indígena, los municipios -junto con sus alcaldías- dejarán de existir y serán sustituidos por los gobiernos autónomos basados en las formas organizativas y principios propios de cada pueblo, supuestamente apartidarios y desvinculados del sistema de la democracia liberal. Eso supondría la pérdida de cuotas de poder tanto a nivel local como nacional, ya que las fuerzas políticas establecidas en el municipio no podrían controlar los recursos económicos, que en el caso del Chaco se vinculan directamente con enormes dividendos por la explotación de hidrocarburos:

El gobierno no quiere la autonomía... Claro, no. Porque sabemos que con la autonomía va a haber un gobierno más transparente y también mejor fiscalización, control, eso no les conviene porque siempre están queriendo joder para que este proceso no vaya adelante, porque en este proceso que nosotros estamos luchando ya no hay color político, no hay nada. ${ }^{10}$

Lo que pasa es que nosotros tenemos los megacampos más grandes gasíferos y no van a querer autonomía. ${ }^{11}$

De esta manera, a consecuencia de una legislación intencionalmente deficiente que no permite la reterritorialización descolonizadora e impone como

\footnotetext{
${ }_{9}$ Entrevista con el mburuvicha Castro Balaza, capitán zonal de Santa Rosa, municipio de Huacaya, el 17 de abril del 2017.

${ }^{10}$ Entrevista con el mburuvicha histórico Calisto Hinojosa, en Santa Rosa, municipio de Huacaya, el 17 de abril del 2017.

${ }^{11}$ Entrevista con Heidy Aruchari Ruiz, asambleísta estatutaria, en Santa Rosa, municipio de Huacaya, el 16 de abril del 2017.
} 
ejecutores del proceso autonómico al municipio y sus estructuras de gobierno liberales, partidarias y lógicamente opuestas a su propia desaparición, el Estado dinamita el proyecto indígena y lo condena si no al fracaso, por lo menos a una sujeción subordinada a los viejos poderes. De hecho, frente a las trabas puestas por el gobierno municipal, algunos dirigentes decidieron negociar con las fuerzas políticas locales, para de esta manera convencerlas para que apoyen o, al menos, no saboteen sus esfuerzos autonómicos.

El problema del sabotaje por parte de la alcaldía se tradujo en otros dos grandes obstáculos para el proyecto autonómico: la falta de recursos y la cooptación y/o persecución de los dirigentes. El primero de los temas es clave para entender la lentitud del proceso, la precariedad en la que se tiene que desenvolver, las barreras materiales que tiene que superar para que, por ejemplo, se desarrollen los trabajos de la asamblea estatuyente, se imprima el Estatuto, se convoquen cabildos con los capitanes comunales y zonales, se socialice adecuadamente el documento y los argumentos a favor de la autonomía, y finalmente se lleve a cabo el referéndum autonómico: "El año pasado nos quedamos con ganas de querer entrar [al referéndum], pero no teníamos los recursos asegurados". ${ }^{2}$

El hecho de que la financiación del camino legal hacia la autonomía dependa del gobierno municipal y sus proyecciones presupuestarias anuales, sujeta el proceso a la voluntad de los grupos de poder vinculados con el sistema de partidos regidos por lógicas y vicios de la política tradicional, lo que constituye un freno intencional desde las estructuras estatales a las ambiciones autonómicas de los pueblos indígenas. Así, con frecuencia el municipio se niega a destinar fondos para la autonomía o pone a los dirigentes ante una difícil elección: dinero para los proyectos en las comunidades o para el referéndum, haciendo que los capitanes guaraníes entren en conflicto con sus bases, cada vez más convencidas de que el proyecto autonómico es un "desperdicio de dinero" que les está quitando los recursos necesarios para su desarrollo productivo y la provisión de servicios básicos. Por lo tanto, tener que sacrificar momentáneamente las demandas materiales de las bases para financiar el proyecto autonómico introduce una gran contradicción en el proceso y le resta apoyos entre las bases comunitarias.

En este sentido, se recuerda con nostalgia las épocas anteriores al gobierno del MAS y a la estatalización de las autonomías, cuando las organizaciones buscaban apoyos sin tener que depender del gobierno central o municipal, con una importante participación de las organizaciones no gubernamentales (ONGs), las mismas que en la actualidad fueron censuradas,

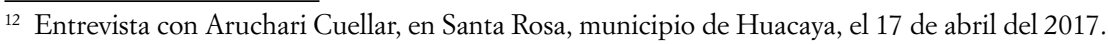


perseguidas o intimidadas por el gobierno del MAS, ${ }^{13}$ provocando el recorte de esta fuente de financiación y ayuda. Las organizaciones propias como la APG, actualmente con dirigentes cercanos al oficialismo, si bien no sabotean el proceso autonómico, tampoco demuestran una gran determinación para apoyarlo. Esto se relaciona con un fenómeno mucho más amplio: la política de infiltración, división y subordinación clientelista de los movimientos sociales por los sucesivos gobiernos del MAS; en este artículo no desarrollaremos este fenómeno, pero que merece ser tomado en cuenta.

En sus testimonios, los y las dirigentes denuncian la perversidad del sistema de financiación que desde el inicio aborta la autonomía del proceso al indicar que debería ser el Fondo de Desarrollo Indígena Originario Campesino $(\text { FONDIOC })^{14}$-considerado una conquista de la lucha del pueblo guaraní y que actualmente es el símbolo de la corrupción gubernamental-, el que proporcionara los recursos para el proceso, que serían autónomos y gestionados por los mismos dirigentes guaraníes, y de ninguna manera sujetos a la arbitrariedad del gobierno central ni del municipal.

La falta de recursos tiene como consecuencia la escasa socialización entre las bases de la versión final del Estatuto, tras las modificaciones impuestas por el TCP. Este trabajo era necesario teniendo en cuenta el mecanismo de referéndum, donde la decisión se toma a base de votos individuales. Los dirigentes entrevistados ven la necesidad urgente de "hacer caminar la autonomía" entre las comunidades para que las bases vuelvan a recordar la importancia del proyecto, vean sus beneficios y acepten el nuevo Estatuto autonómico. De hecho, la falta de información y la escasa implicación de las bases en el proceso constituye, según nuestros interlocutores, uno de los mayores obstáculos en el camino autonómico: "Si le preguntas a la gente para qué es la autonomía, no lo saben. Pensábamos que ellos también sabían, pero no". ${ }^{15}$ Esta actual falta de compromiso por parte de las bases, mencionada por algunos dirigentes y comunarios entrevistados, sería resultado de la burocratización del camino autonómico que alargó

\footnotetext{
${ }^{13}$ Véase el caso del Centro de Documentación e Información de Bolivia, una de las ONG de apoyo a las luchas indígenas de las tierras bajas.

${ }^{14}$ El FONDIOC, que estaba pensado originalmente para incentivar la inversión productiva en las comunidades indígenas y sus fondos provenían del 5 \% del Impuesto Directo a los Hidrocarburos, resultó servir a los funcionarios del MAS, indígenas o no, igual que a las Fuerzas Armadas e incluso al gobierno, para financiar actos de corrupción individual y colectiva a favor del oficialismo. Así, se malversaron sumas millonarias sin que ningún proyecto productivo se llevara a cabo. Véase Saavedra (2015) y Ayo (2016).

15 Entrevista con Heidy Aruchari Ruiz, asambleísta estatutaria, en Santa Rosa, municipio de Huacaya, el 16 de abril del 2017.
} 
sus tiempos y separó a las comunidades, que al inicio estaban involucradas orgánicamente en los trabajos de la asamblea estatutaria, del resultado final de sus trabajos.

También hay que destacar la total contradicción entre las formas tradicionales de gobierno y organización guaraní y las formas liberales del proceso autonómico impuestas por el Estado. Por una parte, tenemos el mecanismo tradicional colectivo de toma de decisiones donde los capitanes representan a sus comunidades en las asambleas regionales y en el marco de sus propias organizaciones, como el Concejo de Capitanes Guaraní de Chuquisaca y la APG. Por otra parte, el futuro de su proyecto es decidido "en la cancha" del Estado, donde no se tiene en cuenta sus decisiones y se imponen los mecanismos liberales, como el referéndum, donde el voto individual decide sobre la colectividad. Así, la socialización directa con cada uno de los comuneros, por encima de las formas asamblearias y colectivas, se vuelve crucial a la hora de asegurar el "sí" para la autonomía.

A la falta de recursos y al consiguiente problema de socialización de la agenda autonómica se añade el tercer gran obstáculo, la cooptación y la división de las dirigencias, promovidas por la alcaldía y el gobierno central, que se inscriben en las acciones del sabotaje oficialista anteriormente mencionadas. Tal como denuncian los mburuvichas, existe una fuerte presión, tanto de cooptación prebendaria como de criminalización y chantaje directo sobre los dirigentes ejercida por la alcaldía y el gobierno central, ambos del MAS, para que abandonen o, en el mejor de los casos, negocien la agenda autonómica y alinearse con las directivas del partido: "Y el gobierno es lo que está buscando, el gobierno busca. Hay cientos de dirigentes que vos le das unos 5 pesos y hacen lo que quieres, entonces ya estamos arreglados. [...] O te alineas o te alineas con plata o sin plata, te rebuscan de todo." 16

En este sentido, los esfuerzos del oficialismo primero están dirigidos a impedir una autonomía institucional y si ésta, a pesar de todo, se consiguiera intentan subordinarla a las políticas estatales a través de los dirigentes alineados. Los insumisos se arriesgan a ser "descabezados", es decir, difamados ante sus comunidades, relegados al margen de las organizaciones y muchas veces son obligados a migrar bajo el asedio de los seguidores de la alcaldía. Todo esto provoca una gran división dentro de las organizaciones, entre los dirigentes, entre las comunidades e incluso en las familias, donde la línea de quiebre no se traza sólo entre los partidarios o no de la autonomía, sino también frente a los presuntos "traidores" de la causa autonómica, donde

${ }^{16}$ Entrevista con Heidy Aruchari Ruiz, asambleísta estatutaria, en Santa Rosa, municipio de Huacaya, el 16 de abril del 2017. 
la sospecha, la desconfianza y recelo ante el protagonismo de unos cuantos se apoderan de los autonomistas antaño unidos.

Esto nos lleva a otro de los factores claves, la desconfianza de las bases ante un posible "acaparamiento" de la autonomía por una o dos familias o unos cuantos dirigentes, que la usen como una oportunidad personal de enriquecimiento y acumulación de capital político. De ahí, las bases son disuadidas de apoyar el proceso frente a la sospecha de que se trataría sólo de un recambio de élites o grupos de poder, donde los políticos de antes serían sustituidos por los nuevos "caciques" guaraníes, igualmente alineados con las directivas partidarias, sin que esto signifique cambio alguno en la forma de entender y ejercer el poder y relacionarse con las bases. "No queremos una autonomía para unos pocos", dicen, y la desconfianza ante los dirigentes a cargo del proceso vistos como incapaces de garantizar la transparencia de los gobiernos autonómicos ni el respeto hacia los nobles principios estatutarios, se apodera de las comunidades:

Ahorita estamos viviendo en Huacaya un fenómeno muy interesante, que la gente de base no quiere autonomía [...] Piensan que la autonomía es para unos cuantos, unos cuantos elegidos a la sede del gobierno y no es así. El gobierno indígena, la autonomía indígena somos todos. Y eso es lo que tenemos que trabajar. ${ }^{17}$

Este tipo de tensiones dentro del campo autonómico, sin importar cuales sean las verdaderas intenciones de los nuevos dirigentes - "autonomía para unos pocos" o "autonomía para todos"-, minan y desgastan en su conjunto un proceso ya de por sí complicado y contradictorio.

Otro tema crucial para entender las contradicciones y limitaciones de una posible autonomía indígena se relaciona con la agenda extractivista del Estado. Los dirigentes conciben la autonomía principalmente como un medio para proteger su territorio y sus recursos naturales y asegurarse la decisión autónoma y soberana sobre éstos. Sin embargo, estas ambiciones distan mucho de una realidad en la cual se impone el interés del Estado, que es presentado en los discursos oficiales como "interés general/nacional”, por encima de los derechos indígenas y los principios plurinacionales.

De hecho, el tema de la consulta previa ${ }^{18}$ fue uno de los más reñidos en los trabajos de la asamblea estatutaria de Huacaya. De ahí que la primera

\footnotetext{
${ }_{17}$ Entrevista con Heidy Aruchari Ruiz, asambleísta estatutaria, en Santa Rosa, municipio de Huacaya, el 16 de abril del 2017.

${ }^{18} \mathrm{La}$ queja frecuente en Huacaya es la falta rutinaria de la consulta, puesto que el municipio no posee el título del TIOC, así que no está reconocido como "indígena". El tema provoca conflictos entre municipios y territorios, entre las poblaciones que sí son consultadas y las otras que son omitidas, por las recompensas negociadas a espaldas de unas y en beneficio de otras.
} 
versión del Estatuto autonómico presentada ante el TCP contemplaba una consulta sujeta a la ley interna autonómica que permitiría la radicalización de este mecanismo legal, con el objetivo de garantizar la soberanía guaraní sobre los recursos existentes en su territorio; sin embargo, fue uno de los puntos estatutarios más observados:

Nosotros en el estatuto hemos puesto el tema de la consulta, amparada en el Convenio 169 y en la CPE. Este artículo nos lo han observado mucho porque nosotros hemos puesto que esto va a ser sujeto a una ley autonómica del territorio autónomo. [...] Nos lo sacaron de un plumazo. ${ }^{19}$

Por lo tanto, la versión final del Estatuto, corregida según las exigencias impuestas por los poderes ajenos a la asamblea estatuyente, sujeta la consulta previa a las leyes centrales, donde el gobierno autonómico queda reducido a ser un mero gestor según "los procedimientos propios", sin derecho a veto, pero sí a los beneficios económicos derivados de la explotación de sus recursos. El hecho de subordinar la consulta previa a las "leyes en vigencia" establecidas por el Estado central, sin mencionar su carácter vinculante y con el énfasis puesto en las recompensas económicas, sin posibilidad legal de cancelar los proyectos, pone de manifiesto que la autonomía "permitida por el Estado" no protege, como se esperaba, ante las actividades extractivas y el despojo que conllevan. Como máximo sería una copia de los mecanismos ya existentes (Convenio 169 de la OIT) ${ }^{20}$ que, no obstante, están subordinados a la legislación nacional ${ }^{21}$ que limita considerablemente sus alcances, sin hablar de las prácticas gubernamentales concretas que tienden a conculcar cualquier legislación nacional o internacional.

En las conversaciones, los y las dirigentes denuncian el proceder del gobierno del MAS, derivado de su apuesta extractivista, que viola flagrantemente los derechos indígenas oficialmente reconocidos, por una parte a través de la promulgación de decretos inconstitucionales que viabilizan la explotación de hidrocarburos en territorios indígenas y áreas protegidas y, por otra parte, con el carácter fraudulento y no vinculante de la consulta que en la práctica se convierte más bien en una herramienta de legitimación

\footnotetext{
${ }^{19}$ Entrevista con Heidy Aruchari Ruiz, asambleísta estatutaria, en Santa Rosa, municipio de Huacaya, el 16 de abril del 2017.

${ }^{20}$ Consultado el 05.07.2018, en https://www.oacnudh.org.gt/estandares/docs/Instrumentos/ Pueblos/169.pdf.

${ }^{21}$ Véanse Bolivia - Decreto Supremo n. ${ }^{\circ} 2366,20$ de mayo del 2015 sobre la exploración y explotación de hidrocarburos en áreas protegidas del país; Ley n. ${ }^{\circ} 535$ de Minería y Metalurgia del 28 de mayo del 2016; Ley n. ${ }^{\circ} 222$ de la Consulta a los Pueblos Indígenas del TIPNIS del 10 de febrero del 2012. Consultados el 10.12.2017, en http://www.gacetaoficialdebolivia.gob.bo.
} 
del despojo, donde se compran las conciencias con sumas ridículas que no pueden reparar los daños sufridos y donde el "sí" se convierte en obligatorio:

Además, nosotros estamos en nuestro libre derecho de decidir si queremos o no queremos estos proyectos hidrocarburíferos en nuestros territorios. No, que la consulta es para que ustedes digan que sí. La consulta es para que nosotros digamos si es que queremos o no queremos esto. ${ }^{22}$

De nada va a servir la consulta porque al final termina uno negociando. Es para legitimar, para legalizar. En realidad se termina negociando. Y no tienen un valor monetario los daños. ${ }^{23}$

El conflicto por los recursos naturales, principal factor de la parálisis de los procesos autonómicos indígenas por parte del gobierno central, consiste no sólo en trabas legales, prácticas fraudulentas en cuanto a la consulta previa o intentos de cooptación por prebendas, sino que conlleva una importante dosis de violencia directa ejercida por el aparato estatal contra las comunidades y sus dirigentes, que se oponen a la exploración y explotación hidrocarburífera sin consulta previa. Este es el caso de Tacovo Mora mencionado con tristeza por nuestros interlocutores, donde la población guaraní se opuso a los trabajos de la empresa nacional Yacimientos Petrolíferos Fiscales Bolivianos (YPFB) en sus territorios y como consecuencia fue brutalmente reprimida por las fuerzas del orden, sus dirigentes fueron arrestados y posteriormente descalificados políticamente. ${ }^{24}$

Esto nos lleva a otra cuestión clave en el debate autonómico, el carácter alternativo de las autonomías indígenas visto como un horizonte de emancipación y su posible pérdida ante la tendencia predominante de copiar los viejos modelos municipales y ceder ante las inercias estructurales. En este sentido, se trataría de un obstáculo interno en el proceso autonómico que exige una profunda autorrevisión del proyecto guaraní a fin de evitar que la autonomía se convierta en una simple reproducción del municipio, esta vez con un rostro indígena. La conciencia del peligro inminente de "caer

\footnotetext{
${ }^{22}$ Entrevista con Heidy Aruchari Ruiz, asambleísta estatutaria, en Santa Rosa, municipio de Huacaya, el 16 de abril del 2017.

${ }^{23}$ Entrevista con Erwin Cuellar, dirigente y líder histórico guaraní, en el municipio de Gutiérrez, el 14 de abril del 2017.

${ }^{24}$ El 18 de agosto del 2015 tuvo lugar en Yateirenda, en la Tierra Comunitaria de Origen guaraní Tacovo Mora en el Chaco cruceño, una brutal represión policial contra los comunarios guaraníes, incluidas mujeres y niños, que fueron intervenidos en sus casas, agredidos y arrestados por haberse opuesto a la explotación del gas en su territorio ancestral por la empresa estatal YPFB, sin consulta previa, libre e informada.
} 
en lo mismo" está presente tanto entre los dirigentes como entre las bases y explicaría la disminución de su apoyo al proyecto autonómico:

Lo que queríamos en el Estatuto de que se puedan generar otros modelos económicos ligados al respeto a la naturaleza. [...] Porque si yo tengo una idea que con la autonomía indígena voy a mejorar la calidad de vida solo de mí y de mi familia y no de mi comunidad, estamos perdidos porque estamos repitiendo el mismo modelo de los políticos de siempre. No queríamos la política pero estamos cayendo en lo mismo. [...] Están con la lógica: vamos a ser autónomos y ahora cuanto de IDH [Impuesto Directo a los Hidrocarburos] nos corresponde. ${ }^{25}$

Esta tensión entre una autonomía concebida como alternativa a los modelos políticos, económicos y sociales predominantes a nivel nacional, donde el pueblo guaraní pueda ser realmente libre y autodeterminarse en su territorio ancestral, y la autonomía "de derecho" permitida por el Estado, condicionada, subordinada e infiltrada por sus lógicas e intereses, es la que explica, además de los factores mencionados, la victoria del "no" en el referéndum autonómico de Huacaya; quizás se trata de un "no" de protesta contra una autonomía no autónoma.

\section{(In)conclusiones}

Es posible afirmar que en el proceso de la Autonomía Guaraní en el Chaco boliviano, concretamente en la experiencia de Huacaya, confluyen de forma compleja y entrelazada diversos niveles que entran en tensión a la hora de definir la forma y el propio contenido de la autonomía. Por un lado los sujetos indígenas, en particular los/las asambleístas que elaboraron el estatuto, resignifican en un discurso autonómico, presentado como propiamente guaraní, un conjunto de prácticas "semiautónomas" y experiencias organizativas de las últimas décadas, tejidas progresivamente a partir de su articulación territorial y política en capitanías a través de la APG. Por otro lado, se toman en cuenta las formas comunitarias de matriz ancestral que expresan los modos de organización político-territorial del pueblo guaraní, donde se evidencia la oficialización de las prácticas de autogobierno guaraní de facto, desarrolladas a través de esta "red de relaciones asamblearias" que también es la APG.

En este sentido, es posible ligar igualmente las luchas de los guaraníes por el reconocimiento cultural como pueblo y el derecho a la autodeterminación en los territorios que habitan como una posibilidad de obtener

\footnotetext{
${ }^{25}$ Entrevista con Heidy Aruchari Ruiz, asambleísta estatutaria, en Santa Rosa, municipio de Huacaya, el 16 de abril del 2017.
} 
una autonomía territorial con un horizonte político que va más allá de las autonomías municipales, regionales y departamentales reconocidas en la actual Constitución. De esta manera, la autonomía tal y como se plantea desde los mismos sujetos sería una modalidad de descolonización política, territorial y sociocultural. Asimismo, la demanda autonómica surge de un imaginario social y territorial anterior al Estado nación, e incluso a la colonia, con una carga histórica que cuestiona explícitamente el diseño político-territorial "colonial" sobre el que fue estructurado y organizado el territorio estatal boliviano.

El tránsito hacia un Estado plurinacional y "con autonomías" (específicamente de tipo étnico-originario) implicaba romper con el "monopolio de la política" presente en toda la historia estatal en Bolivia; es decir, abría la posibilidad constitucional de instaurar y desarrollar una pluralidad de espacios y formas de autogobierno que se concretarían a través de autonomías indígenas. No obstante, en el actual decenio se ha pasado de un proceso constituyente generado por movimientos indígenas, en el que estos estarán subordinados o ausentes, a un período en que el gobierno, con Evo Morales a la cabeza, pronto empezó a desplegar una política destinada a abortar, frenar o subordinar las autonomías indígenas.

Como podemos suponer, estos esfuerzos por parte del Estado, tanto en el ámbito local como central, se deben a los modelos políticos y económicos promovidos por los gobiernos del MAS, que corresponden a un horizonte nacionalista en cuanto a lo político, y en el modelo económico basado en el extractivismo, en una clara contradicción con los derechos territoriales de los pueblos originarios. Este carácter extractivista del actual Estado boliviano se evidencia con más fuerza precisamente en regiones como el Chaco, tradicionalmente marcado como zona de explotación hidrocarburífera. Así, el control sobre los recursos no renovables y los excedentes que producen, al igual que sobre el territorio donde se encuentran, se convierte en el tema clave para entender el actual proceso autonómico y sus dificultades.

Como hemos visto al analizar el caso de Huacaya, que más allá de sus peculiaridades puede ser ilustrativo y extensivo a otros procesos de autonomías "de derecho", las diferentes formas de presión y control político y estatal hacia el pueblo guaraní para impedirle que pueda ser autónomo, determinan en gran medida el éxito y el alcance del desafío autonómico, llevando al desgaste y vaciamiento de su sentido comunitario y transformador. Por lo tanto, las autonomías institucionales (otorgadas por el Estado) presentan varias contradicciones, en su mayoría causadas y propiciadas por el mismo Estado moderno, liberal-capitalista y esencialmente monopólico: frente a la demanda de la descolonización y autodeterminación político-territorial de 
los pueblos indígenas y las naciones originarias, se preservan las estructuras administrativas coloniales y/o republicanas monoculturales y se impone la soberanía estatal sobre los recursos naturales no renovables justificada por el modelo extractivista. Contra las formas de autogestión y autogobierno propias de los pueblos indígenas, se imponen procedimientos burocráticos liberales que desconocen la deliberación colectiva, al promover el voto individual, la sujeción partidaria y la cooptación clientelista. Asimismo, las "autonomías oficiales" (de derecho), aunque hayan sido "una conquista" de las luchas indígenas, parecen no sólo limitadas en cuanto a su alcance emancipador, sino que apuntan a desmantelar la autonomía de facto practicada por los pueblos y abortar su carácter de alternativa societal. En este sentido, las bases están convencidas de que la autonomía, tal y como es consentida por el Estado, no sólo no permite su mayor autodeterminación, sino que al contrario, puede significar una mayor sujeción al Estado y a las nuevas élites caciquiles en el interior de las propias organizaciones indígenas, tras la desarticulación de su fuerza organizativa de base realmente autónoma, como aciertan algunos dirigentes al decir que con la autonomía tienen en sus tierras más Estado que sin ella.

En las últimas décadas el debate en torno a las autonomías político-territoriales ha abierto, especialmente en América Latina, un campo fértil de discusiones teórico-políticas sobre las alternativas sociales, políticas y territoriales a partir de innumerables experiencias locales surgidas desde el "subsuelo de la política" (Tapia, 2008). Dichos procesos autonómicos parecen cuestionar, por una parte, al capital, no sólo como modalidad de acumulación sino como forma de organización humana y, por otra parte, a los mismos Estados nacionales, como modalidades de organización de la vida política de la sociedad (Zibechi, 2008). A la vez, gran parte de estos procesos autonómicos se presentan como espacios político-societales donde se entretejen embrionariamente relaciones horizontales, cooperativas y de reciprocidad, además de una gran diversidad de formas alternativas productivas, democráticas y de gestión de los "bienes comunes". Esta idea de autonomía cuestiona también, de forma radical, incluso la concepción de democracia (liberal) que habría cristalizado como dogma hegemónico $\mathrm{y}$, acaso, como forma política dominante. Al mismo tiempo, la autonomía como noción profundamente política actualizará viejas discusiones teórico-políticas en torno a la autodeterminación, así como su relación con otros conceptos tan antiguos como la emancipación, la democracia y la libertad.

Queda preguntarnos si el camino abierto por las luchas indígenas que apuntaba hacia el reconocimiento estatal de sus reivindicaciones, realmente los acerca a su objetivo principal, es decir, a su reconstitución 
como pueblos y su autodeterminación en el territorio ancestral. ¿No será que la autonomía de derecho está ahogando el espíritu emancipador de la propuesta autonómica indígena y obstaculizando las aspiraciones de lograr una verdadera reconstitución político-territorial de los pueblos, más allá del Estado nación? Sin duda, los mismos sujetos autonómicos deben dar respuesta a esta y otras cuestiones urgentes que surgen a la hora de concebir su relación con el Estado.

Revisado por José Morales

\section{Referencias bibliográficas}

APG - Asamblea del Pueblo Guaraní (2006), Ore Ñemongeta. Propuesta bacia la Asamblea Constituyente. Santa Cruz de la Sierra: APG.

Ayo, Diego (2016), El fondo indígena, un modelo "vicioso" de gestión pública. La Paz: Fundacion Pazos Kanki.

Burguete Cal y Mayor, Araceli (2010), "Autonomía: la emergencia de un nuevo paradigma en las luchas por la descolonización en América Latina”, in Miguel González; Araceli Burguete Cal y Mayor; Pablo Ortiz (coords.), La autonomía a debate: autogobierno indígena y Estado plurinacional en América Latina. Quito: FLACSO-Ecuador, 63-94.

CPE - Constitución Política del Estado Plurinacional de Bolivia (2009), La Paz: Gaceta Oficial/Estado Plurinacional de Bolivia. Consultada el 01.04.2017, en http://www. ademaf.gob.bo/normas/cpe.pdf.

Exeni, José Luis (2015), "Bolivia: las autonomías frente al estado plurinacional", in Miriam Lang; Belén Cevallos; Claudia López (comps.), ¿Cómo transformar? Instituciones y cambio social en América Latina y Europa. Quito: Fundación Rosa Luxemburg/Ediciones Abya Yala, 145-190.

Garcés, Fernando (2013), Los indígenas y su Estado (pluri)nacional: una mirada al proceso constituyente boliviano. Buenos Aires/Tarija/Cochabamba: CLACSO/JAINA/ FHyCE-UMSS.

LMAD - Ley Marco de Autonomías y Descentralización n. ${ }^{\circ}$ 031, de 19 de julio (2010), La Paz: Estado Plurinacional de Bolivia. Consultado el 10.05.2017, en http://www. ftierra.org/index.php/component/attachments/download/24.

Makaran, Gaya; López Pabel (2018), Recolonización en Bolivia: neonacionalismo extractivista y resistencia comunitaria. México: CIALC-UNAM/Editorial Bajo Tierra.

Makaran, Gaya; López, Pabel; Wahren, Juan (coords.) (2019), Vuelta a la autonomia. Debates y experiencias para la emancipación social desde América Latina. Buenos Aires: CIALC-UNAM/ Bajo Tierra A.C./El Colectivo. 
Saavedra, José Luis (2015), “Corrupción en el Fondo Indígena de Bolivia”, Pukara, 105, 9-12.

Santos, Boaventura de Sousa (2010), Refundación del Estado en América Latina, Perspectivas desde una epistemología del Sur. Lima: Instituto Internacional de Derecho y Sociedad/Programa Democracia y Transformación Global.

Tapia, Luis (2002), La condición multisocietal: multiculturalidad, pluralismo, modernidad. La Paz: CIDES-UMSA/Muela del Diablo.

Tapia, Luis (2007), "Gobierno multicultural y democracia directa nacional”, in Álvaro García Linera; Luis Tapia Mealla; Raúl Prada Alcoreza (coords.), La transformación pluralista del Estado. La Paz: Comuna/Muela del Diablo, 93-197.

Tapia, Luis (2008), Política salvaje. La Paz: CLACSO/Comuna/Muela del Diablo.

Tapia Mealla, Luis (2011), "La configuración de un horizonte contra hegemónico en la región andina”, Utopía y Praxis Latinoamericana, 16(53), 119-125.

Zibechi, Raúl (2008), Autonomías y emancipaciones. América Latina en movimiento. México: Editorial Bajo Tierra.

Recibido: 07.09.2018

Aceptación comunicada: 20.12.2019

\section{Pabel Camilo López Flores}

CIDES-UMSA - Postgrado en Ciencias del Desarrollo, Universidad Mayor de San Andrés Avenida 14 de septiembre, 4913, La Paz, Bolivia

Contacto: velpalopezflo@gmail.com

ORCID: https://orcid.org/0000-0002-7180-6584

\section{Gaya Makaran}

CIALC-UNAM - Centro de Investigaciones sobre América Latina y el Caribe,

Universidad Nacional Autónoma de México

Avenida Universidad 3000, Torre II de Humanidades piso 3, Ciudad Universitaria,

Delegación Coyoacán, Ciudad de México CP. 04510, México

Contacto: makarangaya@gmail.com

ORCID: https://orcid.org/0000-0002-6343-0003 
Indigenous Autonomy in Dispute: Between Community Reconstruction and State Tutelage. The Guaraní Experience of Huacaya in Bolivia

Almost a decade after the approval of the Bolivian Constitution which allows for the creation of indigenous autonomies, at present most of the autonomous processes do not seem to moving in the expected direction. What happened to the Autonomias Indigenas Originarias Campesinas (AIOC) as one of the most transformative components of the plurinational project in Bolivia? In this work, we try to problematize this question, from the processes of indigenous autonomy of the Guaraní people in the Bolivian Chaco, specifically from the municipality of Huacaya. We critically approach this process of "autonomy of law" from the voices of the indigenous subjects themselves, in an effort to rethink the concept of indigenous autonomy and its concrete application in Bolivia.

Keywords: autonomy; Guaraní people; Huacaya (Bolivia); indigenous movement; plurinationality.

\section{Autonomie autochtone en litige: entre la reconstitution communautaire et la tutelle de l'État. L'expérience guarani de Huacaya en Bolivie}

Plus d'une décennie après l'adoption de l'actuelle Constitution bolivienne qui a permis de créer des autonomies autochtones, à ce jour, la plupart des processus d'autonomie ne semblent plus aller dans la direction attendue. Qu'est-il arrivé aux Autonomies autochtones rurales, l'une des composantes les plus transformatrices du projet plurinational en Bolivie? Dans ce travail, nous essayons de problématiser cette question à partir des processus d'autonomie du peuple guarani dans le Chaco bolivien, en particulier dans la municipalité de Huacaya. Nous analysons de manière critique ce processus d' "autonomie de droit" à partir des voix des sujets autochtones eux-mêmes, dans un effort pour repenser à la fois le concept même d'autonomie autochtone et son application concrète en Bolivie.

Mots-clés: autonomie; Guarani (peuple); Huacaya (Bolivie); mouvement autochtone; plurinationalité. 
